\title{
Evaluating the Effects of Minimal Risk Natural Products for Control of the Tick, Ixodes scapularis (Acari: Ixodidae)
}

\author{
Megan C. Dyer, ${ }^{1,2,5}$ Matthew D. Requintina, ${ }^{1}$ Kathryn A. Berger, ${ }^{1,3}$ Gavino Puggioni,, ${ }^{4}$ and \\ Thomas N. Mather ${ }^{1,2}$
}

\begin{abstract}
'Department of Plant Sciences and Entomology, Woodward Hall, University of Rhode Island, Kingston, RI 02881, ${ }^{2}$ Center for Vector-Borne Disease, University of Rhode Island, Kingston, RI 02881, ${ }^{3}$ Current address: Rothamsted Research, Harpenden, UK, ${ }^{4}$ Department of Computer Sciences and Statistics, Tyler Hall, University of Rhode Island, Kingston, RI 02881, and

${ }^{5}$ Corresponding author, e-mail: mdyer@uri.edu
\end{abstract}

Subject Editor: Kevin Macaluso

Received 17 April 2020; Editorial decision 23 July 2020

\begin{abstract}
Knockdown and residual activity of 10 minimal risk natural products (MRNPs), one experimental formulation of nootkatone, and two bifenthrin labels were evaluated against host-seeking nymphal Ixodes scapularis Say using a novel micro-plot product screening system placed in a landscape setting similar to a wooded residential property. The MRNPs evaluated included Tick Stop, EcoPCO EC-X, Met52 EC, CedarCide PCO Choice, EcoEXEMPT IC ${ }^{2}$, EcoSMART Organic Insecticide, Essentria IC ${ }^{3}$, privately labeled products 1 and 2 (based on EcoEXEMPT IC ${ }^{2}$ and sold as a professional pest control application), and Tick Killz. Just the nootkatone and 4 of these 10 products tested (EcoPCO EC-X, Met52 EC, EcoEXEMPT IC ${ }^{2}$, and Essentria IC ${ }^{3}$ ) had statistically significant $(P<0.05)$ knockdown effects (killed ticks while active in the arenas) when compared to water-only controls, but only 2 of these, EcoPCO EC-X and nootkatone, displayed significant residual tick-killing activity after weathering naturally in the landscape for 2 wk prior to tick application/testing. Moreover, botanical oil-based products with the same active ingredients provided inconsistent results when tested multiple times across study years.
\end{abstract}

Key words: blacklegged tick, Ixodes scapularis, natural product, botanical oil, tick control

New cases of Lyme disease, the most commonly reported tick-borne disease in the United States, have been increasing consistently annually over the past $20 \mathrm{yr}$, especially in the northeastern United States (Rosenberg et al. 2018, Centers for Disease Control and Prevention [CDC] 2019a). Since 2009, in Rhode Island alone, the Lyme disease incidence rate has increased from 14.2 to 62.5 cases per 100,000 residents compared to the national rate of 7.2 cases per 100,000 (CDC 2019b). Furthermore, it is estimated that more than 400 additional Rhode Island cases go unreported every year (CDC 2019b).

The public generally understands that blacklegged ticks, Ixodes scapularis Say carry the Lyme disease-causing bacterium and transmit it to people and pets during blood feeding (Childs et al. 1998, Herrington Jr 2004, Hook et al. 2015). They are also familiar with the bull's eye rash that is characteristic in most cases of Lyme disease. Although public awareness regarding tick bite-associated health risks is increasing, a large gap in tick bite prevention knowledge and action still exists. Despite being well-versed in the consequences of tick exposure, the public generally foregoes using the most effective tick bite prevention behaviors and activities (Herrington Jr 2004, Gould et al. 2008, Connally et al. 2009, Hook et al. 2015, Butler et al. 2016, Niesobecki et al. 2019). Many factors likely contribute to this, including 1) lack or improper use of protective measures such as repellents and wearing repellent-treated clothes, 2) failure to recognize and avoid tick habitat, and 3) lacking availability of science-based information on the effectiveness of tick-killing products.

Along with host-targeted strategies and landscape manipulations, suppressing the tick population with an area-wide treatment using chemical pesticides can potentially reduce tick encounter risk on residential properties. For control of the blacklegged tick, a broadcast application method often called a 'perimeter spray' is used, in which spraying is targeted at the ecotone habitat most frequented by these ticks in the residential landscape (Piesman 2006, Stafford 2007). If applied correctly using effective products, perimeter sprays can significantly reduce tick encounter risks for family members, including pets, within the treated portions of their own yard (Stafford 2007). However, due to concerns about potential human toxicity/carcinogenicity, environmental contamination (including groundwater), and toxicity toward nontarget 
organisms and pets (Childs et al. 1998, Ginsberg et al. 2017), recent consumer trends suggest that homeowners are embracing newer natural alternatives over industry standard synthetic chemical pesticides which have historically been proven effective (Jordan and Schulze 2019). Though possibly less damaging to the environment, the natural pesticides, which may include various botanical oils, biopesticides, and abrasives, or a combination of these, have not been thoroughly tested. Also, due to their 'natural' active ingredients, they do not fall under the same Environmental Protection Agency (EPA) regulations as do the industry standard chemicals. Most minimal risk natural products (MRNPs) are considered exempt from federal regulation under the Federal Insecticide, Fungicide, and Rodenticide Act (FIFRA), and need not be registered with the EPA, but may need to be listed within the states where they are distributed (U.S. EPA 2020).

Traditionally, field plots used for evaluating efficacy of acaricides to control blacklegged ticks using the 'area-wide' method typically range from $100 \mathrm{~m}^{2}$ to hectares in size and must be replicated extensively to support enough tick collection numbers for statistical analyses. Such studies are labor intensive and expensive, presenting a significant impediment to evaluating and comparing efficacy of tick control products. Moreover, when conducted across residential sites, ecological variability often results in variances much larger than means. This study simultaneously evaluates an array of MRNPs in a novel micro-plot system that simulates ecological conditions found in northeast U.S. residential sites where blacklegged ticks are highly abundant. Using field-derived but laboratoryreared nymphal blacklegged ticks, the tick-killing knockdown and residual activity of some of these MRNPs were compared to highly effective formulations of bifenthrin, the current industry standard which has been proven effective against ticks (Stafford 2007, Elias et al. 2013, Eisen and Dolan 2016).

\section{Materials and Methods}

\section{Field Plot Set-up}

This study was conducted over four nymphal blacklegged tick seasons, June-August (2012-2015), in a plot of woods located at the University of Rhode Island's East Farm. Professional contractors surveyed and prepared the site by cutting down some of the smaller trees to open up the dense tree canopy in Fall 2011, creating a 0.5-ha study area similar to that of a wooded residential property. The site was left undisturbed until the following Spring (2012) to allow restoration of the natural leaf litter. The area was covered by a predominantly oak canopy and the substrate consisted of natural leaf litter and un-mown grasses. Six plots were laid out within the newly established study area, and each of them was further divided into five or six micro-plots, each containing two 0.3-m-diameter PVC rings (arenas) spaced $1.5 \mathrm{~m}$ apart and tampered into the ground (Fig. 1). These arenas were $10 \mathrm{~cm}$ in height and were tampered in leaving only the top 4-5 cm above ground level. Each micro-plot was assigned a different MRNP treatment based on a randomized block design, resulting in a total of six replicates per treatment. The two arenas within each micro-plot represented a knockdown treatment and a residual treatment. On Day 1, a total of 60 first-generation, lab-reared nymphal blacklegged ticks were placed into each knockdown arena to provide a 24-h acclimation and dispersal into the leaf litter prior to applying MRNPs (Fig. 2). The residual arenas were sprayed at the same time as the knockdown arenas but were allowed to weather naturally in the landscape for 2 additional weeks before ticks were added to them on Day 14. This timing enabled us to evaluate whether the product was able to maintain its tick-killing activity in the landscape for $2 \mathrm{wk}$ post-application. Three humidity loggers were placed within the study site to record temperature and relative humidity for the duration of each study season in an attempt to detect any low-moisture events which might negatively impact tick survival (Berger et al. 2014). a.

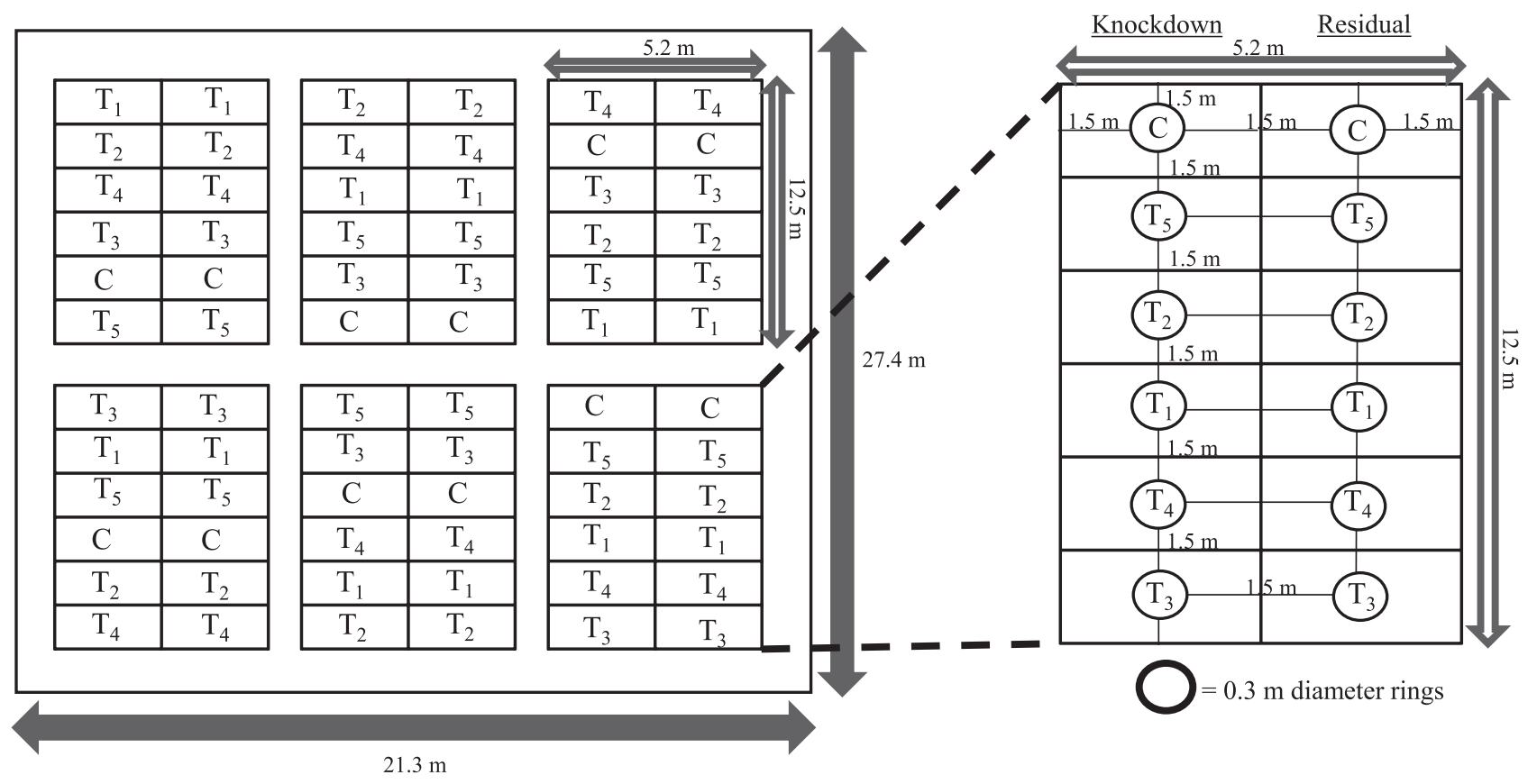

Fig. 1. (a)The study site. A completely randomized block design for 21.3-m $\times 27.4-\mathrm{m}$ simulated residential plot. (b) A single plot (replicate) consisting of six microplots (five treatments and a single water-only control). The left side and the right side are used for the knockdown efficacy trial and residual efficacy, respectively. Treatment areas are 0.3-m-diameter arenas, with $1.5 \mathrm{~m}$ wide buffer. Note: Diagram not to scale. 


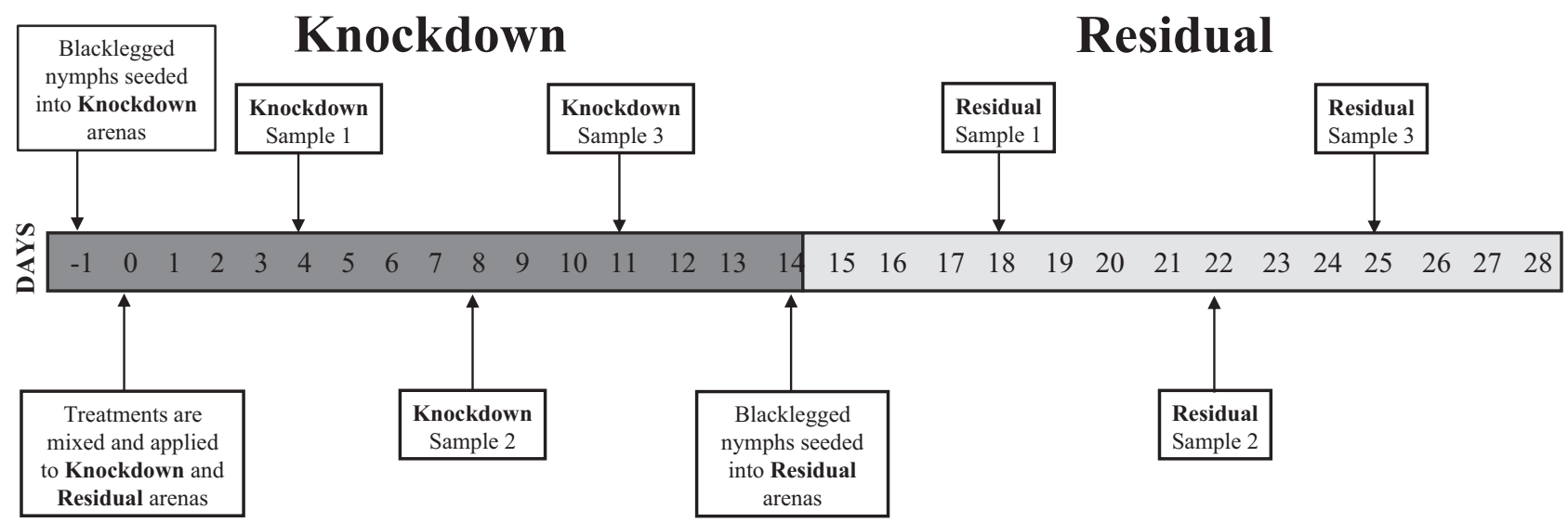

Fig. 2. Timeline of events, including treatment and approximate sampling schedules. Due to inclement weather, sampling days may have been shifted accordingly.

Table 1. Commercially available and experimental formulations of MRNPs evaluated during nymphal Ixodes scapularis seasons

\begin{tabular}{|c|c|c|c|}
\hline Category & Product & Active ingredient & Application rate \\
\hline \multirow[t]{2}{*}{ Biopesticides } & EcoPCO EC-X & Pyrethrins & $25.71 \mathrm{ml} / \mathrm{m}^{2}(2012)$ \\
\hline & Met52 EC & Metarhizium anisopliae & $0.96 \mathrm{ml} / \mathrm{m}^{2}(2012) ; 1.02 \mathrm{ml} / \mathrm{m}^{2}(2013)$ \\
\hline \multirow[t]{8}{*}{ Botanical oils } & CedarCide PCO Choice & Texas red cedar oil & $25.71 \mathrm{ml} / \mathrm{m}^{2}(2013)$ \\
\hline & EcoEXEMPT IC ${ }^{2}$ (w. EcoADJUVANT) & Rosemary oil, peppermint oil & $\begin{array}{l}25.71 \mathrm{ml} / \mathrm{m}^{2} \text { EcoEXEMPT IC }{ }^{2}, 6.43 \mathrm{ml} / \mathrm{m}^{2} \\
\text { EcoADJUVANT (2013) }\end{array}$ \\
\hline & EcoSMART Organic Insecticide & Clove oil, thyme oil & $24.41 \mathrm{~g} / \mathrm{m}^{2}(2015)$ \\
\hline & Essentria $\mathrm{IC}^{3}$ & Rosemary oil, peppermint oil, geraniol & $\begin{array}{l}25.71 \mathrm{ml} / \mathrm{m}^{2}(2012,2013) ; 19.28 \mathrm{ml} / \mathrm{m}^{2} \\
(2014)\end{array}$ \\
\hline & Nootkatone (w. D-Limonene and EZ-Mulse) & Nootkatone, d-Limonene, EZ-Mulse & $\begin{array}{l}1.02 \mathrm{ml} / \mathrm{m}^{2} \text { nootkatone; } 0.96 \mathrm{ml} / \mathrm{m}^{2} \\
\text { D-Limonene, EZ-Mulse }(2013)\end{array}$ \\
\hline & Private Label 1 & Rosemary oil, peppermint oil, geraniol & $16.07 \mathrm{ml} / \mathrm{m}^{2}(2015)$ \\
\hline & Private Label 2 & Rosemary oil, peppermint oil, geraniol & $6.43 \mathrm{ml} / \mathrm{m}^{2}(2015)$ \\
\hline & Tick Killz & Cedarwood oil & $0.64 \mathrm{ml} / \mathrm{m}^{2}(2014)$ \\
\hline Abrasives & Tick Stop & Organic fertilizer & $45.25 \mathrm{~g} / \mathrm{m}^{2}(2014)$ \\
\hline
\end{tabular}

\section{Treatment Preparations and Applications}

The materials evaluated at labeled field rates were commercially available and/or experimental materials (Table 1) and included the following products: Tick Stop (Wildflower Farm, Delhi, NY), EcoPCO EC-X (Prentiss Inc., Alpharetta, GA), Met52 EC (Novozymes Biological Inc., Salem, VA), CedarCide PCO Choice (CedarCide Industries Inc., Spring, TX), EcoEXEMPT IC ${ }^{2}$ with EcoADJUVANT (EcoSMART Technologies Inc., Franklin, TN), EcoSMART Organic Insecticide (EcoSMART Technologies Inc, Roswell, GA), Essentria IC ${ }^{3}$ (Envincio LLC, Cary, NC), Tick Killz (Natural Repellents LLC, Newtown, CT), Talstar Professional (FMC Corp, Philadelphia, PA), and UP-Star Gold (United Phosphorus Inc., Trenton, NJ). Three experimental formulations included nootkatone with d-Limonene (provided by the CDC, Fort Collins, CO), Private label 1 and Private label 2. The nootkatone formulation used followed that which was used in previous research performed by the CDC (Dolan et al. 2009). Both Private Labels were based on the original EcoEXEMPT IC2 formulation, manufactured independently and sold as part of a commercial tick control service. Some of the products were tested more than once because they 1) were a positive control representing the industry standard (bifenthrin), 2) our sampling timeline differed from the product instructions in $1 \mathrm{yr}$ but were followed in a subsequent trial (Met52 EC), 3) we were testing different 'batches' of the same product (Met52 EC, Essentria $\mathrm{IC}^{3}$ ), and/or 4) we were testing different concentrations of the same product (Talstar Professional, Essentria $\mathrm{IC}^{3}$ ) (Tables 2).

Liquid formulations of MRNPs were prepared according to label specifications provided, mixed in 3.78-liter plastic containers and poured into Solo backpack sprayers (Solo Inc., Newport News, VA), where they were hand-pumped to $620.5 \mathrm{kPa}$. A $0.91-$ $\mathrm{m}^{2}$ piece of plastic was used to create a 0.3 -m-diameter cylindrical 'spray shield' which was placed inside of the arenas to prevent over-spray beyond the arenas. The sprayer wand was placed inside of the spray shield, just above the leaf litter, and $30 \mathrm{ml}$ of product was applied in a circular motion, in an attempt to have even distribution of product. The bifenthrin and water-only control plots were treated in the same manner. Dry formulations were weighed into plastic portion cups (one per arena) and distributed evenly using a metal colander. Post-product application, arenas were covered with $1.3-\mathrm{cm}^{2}$ mesh hardware cloth secured with stakes until ready for sampling to prevent disruption from local wildlife.

\section{Sampling}

Arenas were evaluated for $2 \mathrm{wk}$ at 3- to 4 -d intervals after treatment (Fig. 2) using a round 0.3-m-diameter pressboard with a center handle and wrapped in a flannel 'bonnet'; the pressboard covered the entire area of the arena. Each arena was continuously sampled by pressing the board into the leaf litter for 5-s increments (=one 
Table 2. Effect of MRNPs and bifenthrin on Ixodes scapularis nymphs after a single application in June 2012-2015

\begin{tabular}{|c|c|c|c|c|c|c|c|}
\hline \multirow[t]{2}{*}{ Year } & \multirow[t]{2}{*}{ Product } & \multicolumn{3}{|c|}{ Knockdown (KD) } & \multicolumn{3}{|c|}{ Residual (RESID) } \\
\hline & & \# Ticks recovered & $\%$ Control & $P$-value & \# Ticks recovered & $\%$ Control & $P$-value \\
\hline \multirow[t]{4}{*}{2012} & EcoPCO EC-X & 1 & 99.60 & $<0.001 *$ & 76 & 72.40 & $<0.001^{*}$ \\
\hline & Essentria $\mathrm{IC}^{3}$ & 229 & 15.20 & 0.193 & 288 & 0 & 0.988 \\
\hline & Met52 EC & 243 & 10.00 & 0.574 & 277 & 0 & 1.000 \\
\hline & Talstar P & 0 & 100 & $0.001 *$ & 0 & 100 & $<0.001 *$ \\
\hline \multirow[t]{5}{*}{2013} & CedarCide PCO Choice & 152 & 5.00 & 0.999 & 259 & 0 & 0.931 \\
\hline & EcoEXEMPT IC ${ }^{2}$ & 22 & 86.60 & $<0.001 *$ & 152 & 30.20 & 0.355 \\
\hline & Essentria $\mathrm{IC}^{3}$ & 74 & 53.80 & $0.004 *$ & 227 & 0 & 1.000 \\
\hline & Talstar P & 0 & 100 & $<0.001 *$ & 0 & 100 & $<0.001^{*}$ \\
\hline & Met52 EC & 94 & 41.30 & $0.037^{*}$ & 158 & 29.80 & 0.447 \\
\hline \multirow[t]{5}{*}{2014} & Essentria $\mathrm{IC}^{3}$ & 186 & 30.60 & $0.003 *$ & 275 & 6.46 & 0.554 \\
\hline & Nootkatone (w. D-Limonene) & 45 & 83.21 & $<0.001^{*}$ & 229 & 35.37 & $0.006^{*}$ \\
\hline & Tick Killz & 252 & 5.97 & 0.994 & 269 & 8.50 & 0.376 \\
\hline & Tick Stop & 256 & 4.48 & 0.999 & 285 & 3.06 & 0.845 \\
\hline & UP-Star Gold & 1 & 99.63 & $<0.001^{*}$ & 1 & 99.69 & $<0.001^{*}$ \\
\hline \multirow[t]{5}{*}{2015} & EcoSMART Organic Insecticide & 257 & 0 & 0.512 & 297 & 0 & 0.954 \\
\hline & Private Label 1 & 139 & 37.10 & 0.099 & 228 & 17.09 & 0.475 \\
\hline & Private Label 2 & 253 & 0 & 0.922 & 286 & 0 & 0.998 \\
\hline & Talstar P $(100 \%)$ & 0 & 100 & $<0.001^{*}$ & 4 & 98.55 & $<0.001^{*}$ \\
\hline & Talstar P (67\%) & 1 & 99.55 & $<0.001^{*}$ & 0 & 100 & $<0.001^{*}$ \\
\hline
\end{tabular}

Percent control was measured using Abbott's formula.

*Significant differences $(P<0.05)$ between treatment and water-only control plots using Tukey HSD test.

sample, with typically $8-10$ insertions of the pressboard/sample) to collect questing nymphs, until three consecutive samples revealed no additional ticks attached for that session. Using fine-pointed tweezers, all ticks were placed into vials after each sample and results recorded. The same sampling schedule and technique were used for the residual arenas as for the knockdown arenas, except just 2 wk later. Care was taken to keep separate pressboards for each treatment and to launder the flannel bonnets between sample days to avoid cross-contamination.

\section{Nymphal Ticks}

Ticks for these experiments were reared from wild-caught hostseeking females, then fed on rabbits, and fed as larvae on hamsters in the laboratory (Mather and Mather 1990) (University of Rhode Island Institutional Animal Care and Use Committee approved protocol AN08-04-017, originally dated June 2008). Engorged larvae were held under $23.5^{\circ} \mathrm{C} /<95 \% \mathrm{RH}$ and $14 \mathrm{~L} / 10 \mathrm{D}$ until molting. Molted nymphs were held in the incubator for an additional 2-3 mo to ensure active questing behavior before being used in the field experiment. Sixty lab-reared nymphal blacklegged ticks were seeded into each arena, for a total of 360 ticks per treatment.

\section{Statistical Analysis}

Repeated measures analysis of variance (ANOVA) was used for statistical comparisons of nymphal tick counts among treatments and plots using SigmaPlot11 (Systat Software, Inc., San Jose, CA). Knockdown efficacy (KD) and residual activity (RESID) experiments were treated as two separate analyses. Mean differences were analyzed, for both components of the analysis, using Tukey's Honestly Significant Difference (HSD).

Efficacy of pesticide treatments was evaluated by comparing percent control of nymphal tick densities in each treatment plot against water-only control plots. Percent control was calculated using Abbott's formula (Abbott 1925):

\section{Corrected percent ( $\%$ ) control \\ $=\left[1-\frac{n \text { collected from } T \text { after treatment }}{n \text { collected from } C \text { after treatment }}\right] * 100$}

where $n$ is nymphal tick density, $T$ is treated plots, and $C$ is wateronly control plots.

\section{Results}

\section{Trials}

Bifenthrin (Talstar Professional) was highly effective, providing $100 \%$ kill in both the knockdown and 2-wk residual treatments (Table 2; Fig. 3). Among the MRNPs, only the EcoPCO EC-X was found to have a statistically significant impact as both a knockdown (99\% kill) and residual treatment ( $72 \%$ kill) relative to water-only control plots 2 wk post-application. Neither Essentria IC ${ }^{3}$ nor Met52 EC treatments had a significant difference between the abundance of nymphs in either the knockdown or residual treatments when compared to the water-only control plots (Table 2).

\section{Trials}

We extended the time duration between application of Met52 EC and tick sampling to $7 \mathrm{~d}$, following the product label instruction rather than our standard post-application sampling timeline, and observed a statistically significant knockdown effect (41\% kill) compared to the water-only control. The effectiveness of Met52 EC dropped noticeably in the residual arm of the study (Table 2, Fig. 4). The Essentria $I^{3}$ and EcoEXEMPT IC ${ }^{2}$ both exhibited a statistically significant tick knockdown effect, but the Essentria $\mathrm{IC}^{3}$ had a noticeably lesser impact than the EcoEXEMPT IC ${ }^{2}$ and neither formulation was effective as a residual when compared to 


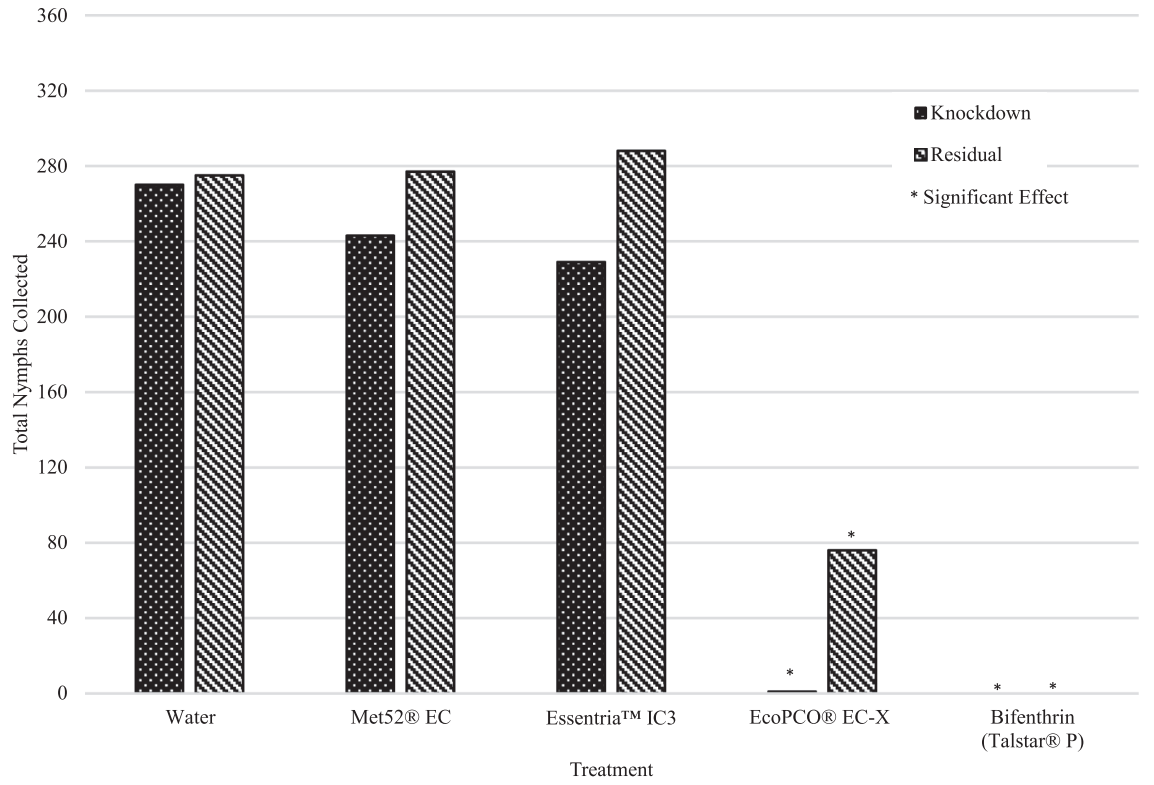

Fig. 3. Total number of Ixodes scapularis nymphs recovered from micro-plots (of 360 total) during 2012 testing.

the water-only control (Table 2). The CedarCide PCO Choice was neither effective as a knockdown nor residual treatment (Table 2). Talstar Professional remained highly effective as a knockdown and residual treatment, even after 3 wk post-application (Table 2 ).

\section{Trials}

Essentria IC $^{3}$ (30.6\% kill) and nootkatone (w. D-Limonene) $(83.2 \%$ kill) had significant knockdown effects when compared to water-only controls, but only the nootkatone (w. D-Limonene) remained effective (35\% kill) as a residual (Table 2, Fig. 5). The residual effect of Essentria $\mathrm{IC}^{3}$ noticeably decreased compared to the knockdown efficacy as in previous trials with this product. Neither of the other products, Tick Killz and Tick Stop, had an effect on the nymphs as a knockdown treatment or as a residual treatment (Table 2). The bifenthrin product (UP-Star Gold, 7.9\% AI) was highly effective as a knockdown and as a residual, this time 4 wk post-application (Table 2).

\section{Trials}

None of the MRNPs tested (Private label 1, Private label 2, and EcoSMART Organic Insecticide) were found to have a significant effect as a knockdown treatment when compared to water-only control plots (Table 2, Fig. 6), and two of the treatments (Private label 2 and EcoSMART Organic Insecticide) had more nymphs recovered than in the water-only control plots (Table 2). All three products also were found to be ineffective as residual treatments, with more nymphs being recovered from the Private label 2 and EcoSMART Organic Insecticide plots than from the water-only controls (Table 2). A onethird lower concentration of Talstar Professional than was used in previous trials was still highly effective as both a knockdown and residual treatment when compared to water-only control plots, and the full-strength application had a similar performance to previous years.

\section{Discussion}

A novel micro-plot system was developed for screening multiple acaricide products under the same environmental conditions and location in the field as a means of screening minimal risk natural products for control of nymphal blacklegged ticks. Compressing large field test sites into single $0.3-\mathrm{m}$ arenas, which were seeded with a known number of first-generation lab-reared nymphs, saved time by sampling small areas, increased robustness through replication under similar environmental conditions, and reduced study costs by providing more efficient treatment application. Spray shields prevented cross-contamination of treatments and allowed use of less product per treatment.

Although there were slight fluctuations of nymphal blacklegged tick recovery from our water-only control plots from year to year, we had an $84.5 \%$ average recovery $(74.5 \%$ from our knockdown arenas and $94.9 \%$ from our residual arenas). The total number of ticks recovered annually from the water-only control plots was used to normalize the data and calculate the efficacy of the products tested each year, to account for any natural/environmental conditions that would negatively impact the survival of the lab-reared ticks.

The synthetic pyrethroid bifenthrin provided consistent tick control. Only one commercially available MRNP, EcoPCO EC-X (pyrethrins) and one experimental product (nootkatone with D-Limonene) provided a high level (>50\% killing) of knockdown control over host-seeking I. scapularis nymphs and, although tickkilling efficacy decreased somewhat in the 2-wk residual study, acaricidal activity of these MRNPs persisted to provide statistically significant levels of tick control.

For the purpose of standardization, in 2012, the sampling timeline for the Met52 EC was kept the same as all the other products, with sampling beginning $3 \mathrm{~d}$ post-application, which was contrary to the label instructions. Under these conditions, Met52 EC did not have a significant impact (Table 2), either as a knockdown or residual application, contrary to previously published reports (Stafford and Allan 2010). In 2013, the sampling timeline for the Met52 EC was adjusted to label instructions, allowing the fungal spores to establish for a full $7 \mathrm{~d}$ prior to tick sampling, and under this longer incubation scenario, this biopesticide provided statistically significant knockdown compared to water-only controls (Table 2), but it did not significantly suppress nymphs in the residual arm of the study. The use of Metarhizium sp. as a biological control agent has been 


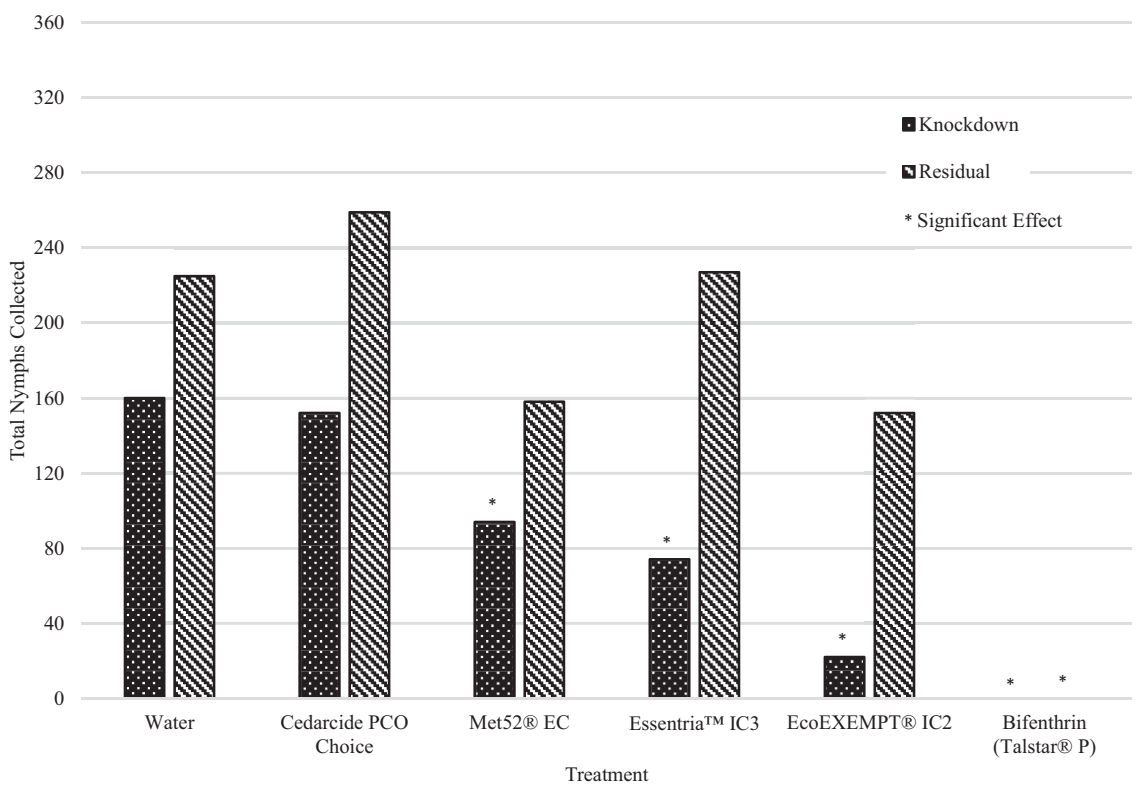

Fig. 4. Total number of Ixodes scapularis nymphs recovered from micro-plots (of 360 total) during 2013 testing.

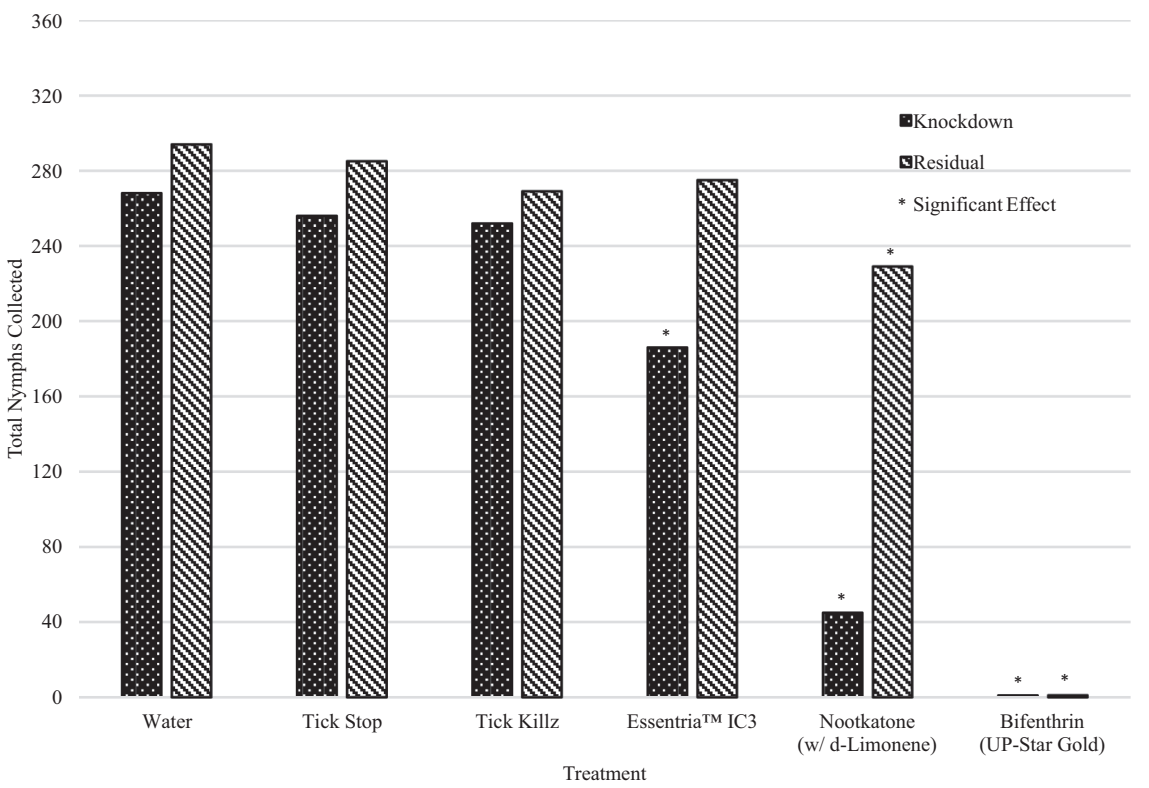

Fig. 5. Total number of Ixodes scapularis nymphs recovered from micro-plots (of 360 total) during 2014 testing.

widely studied against several arthropod pests including blowflies in England (Wright et al. 2004), grasshoppers and locusts in Australia (Hunter 2005), mosquitoes in Mexico and Korea (Garza-Hernandez et al. 2015, Lee et al. 2015), and several species of ticks worldwide (Benjamin et al. 2002, Kirkland et al. 2004, Leemon et al. 2008, Bharadwaj and Stafford 2010, Wassermann et al. 2016) with mixed results. One potential reason for this may be due to variation between several strains of the fungus; each may have a different effect depending on pest species, pest life stage, environmental conditions, spore concentration, and formulation. Another cause of variable results may have been the sampling technique used in the respective study designs. The results from this study were indicative of fungal growth/tick killing under natural field conditions, whereas in some previously published Metarhizium anisopliae studies, ticks were sampled out of plots and returned to the lab to be maintained under ideal conditions for fungal growth (Benjamin et al. 2002, Bharadwaj and Stafford 2010, Stafford and Allan 2010).

Two additional minimal risk natural products exhibited a significant knockdown effect; in 2013, both the EcoEXEMPT IC ${ }^{2}$ and Essentria IC $^{3}$ knockdown treatments had significantly fewer ticks recovered than the water-only control. Both of these products contain rosemary and peppermint oils. The newer Essentria $\mathrm{IC}^{3}$ is the replacement formulation of EcoEXEMPT IC ${ }^{2}$ which previously had been shown to be effective against blacklegged ticks (Rand et al. 2010). The EcoEXEMPT IC ${ }^{2}$ required adding an emulsifier prior to dilution and application; in re-formulating the product, an adjuvant was added to Essentria IC $^{3}$ so that the emulsifier was no longer required to keep the oils in suspension. Although still effective, the original 


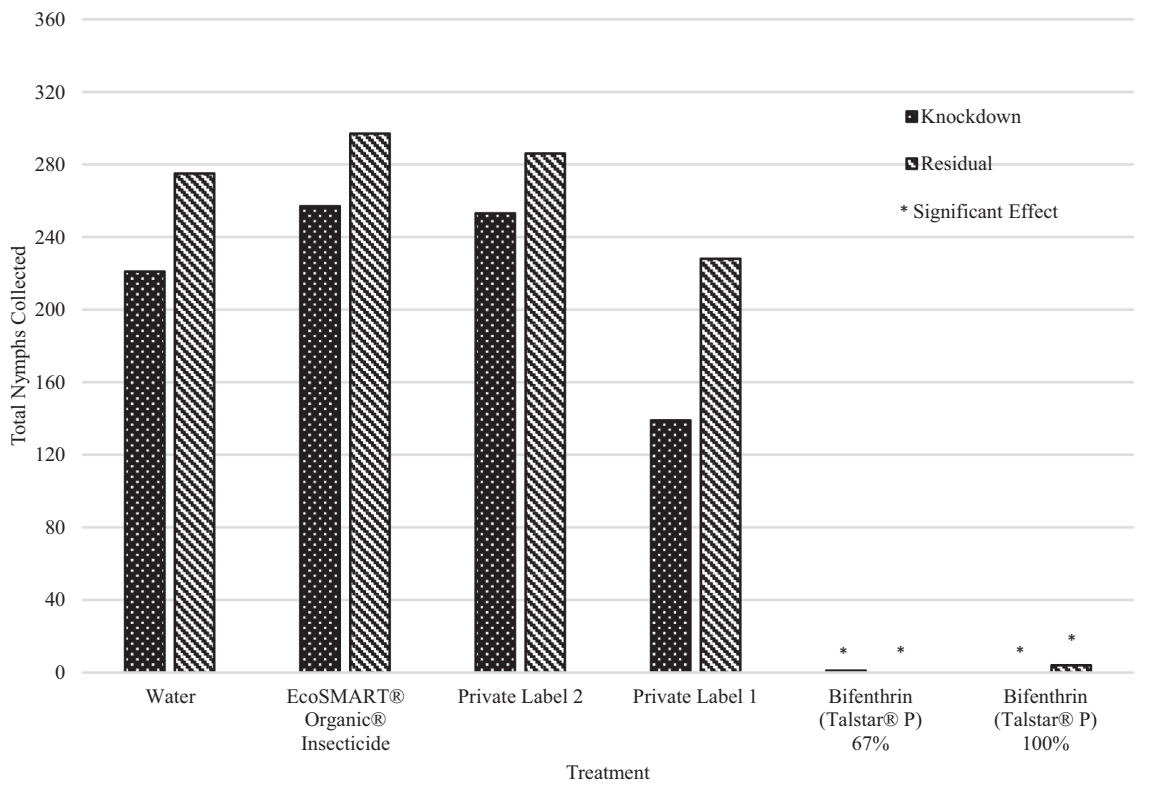

Fig. 6. Total number of Ixodes scapularis nymphs recovered from micro-plots (of 360 total) during 2015 testing.

IC $^{2}$ formulation had a greater impact on host-seeking nymphs than the newer Essentria $\mathrm{IC}^{3}$, but neither product remained active long enough to have a significant impact on the nymphs during the residual studies. It is possible that the greater tick-killing action of the $\mathrm{IC}^{2}$ formulation could be attributed to the emulsifier rather than to the botanical oils (Schroer et al. 2001, Mullin et al. 2015), but this was not tested.

In 2014, nootkatone crystals were dissolved in D-Limonene (a solvent extracted from orange peels) to make a $2 \%$ solution, and then diluted in water containing EZ-Mulse (a proprietary blend of nonionic surfactants used to emulsify citrus extracts and natural oils) (Jordan et al. 2011, Bharadwaj et al. 2012). As in previous studies (Dolan et al. 2009, Jordan et al. 2011, Bharadwaj et al. 2012), this experimental nootkatone formulation exhibited a significant immediate knockdown effect $(83 \%)$ on host-seeking nymphs, and remained active (with lower efficacy) in the 2 -wk residual study (killing $35 \%$ of nymphs released into the arenas $2 \mathrm{wk}$ after product application). Essentria $\mathrm{IC}^{3}$ was tested for a third time, using a less concentrated solution than label rates, and had a significant knockdown effect $(31 \%)$, but no residual effect.

In 2015, two privately labeled products (Private Label 1 and Private Label 2), reportedly based on the original formulation of EcoEXEMPT IC ${ }^{2}$, as well as EcoSMART Organic Insecticide granules showed no significant knockdown or residual effect on hostseeking blacklegged tick nymphs (Table 2 ). In total, five formulations of rosemary and peppermint oil were tested but only two of them exhibited a significant knockdown effect. The observed batch-tobatch variability in efficacy raises concerns regarding formulation of botanical oil products and suggests that steps to improve quality control in formulation might be worthwhile.

One caveat of this MRNP screening study is that results for all products are based on a single application. It is possible that greater tick control than we observed can be achieved with multiple applications of MRNPs during the active tick season. In practical terms, however, with little MRNP residual activity evident in our tests, applications would need to be applied only after vector ticks become active; for nymphal stage blacklegged ticks in the highly endemic Northeastern and mid-Atlantic United States, that would mean starting treatments by mid- to late-May. Assuming an every 2-wk treatment schedule, it would be possible to make four applications before nymph populations begin their normal seasonal decline. Additional studies would be needed to determine if multiple MRNP applications has an impact on tick populations in the residential landscape, as well as the degree of tick encounter protection afforded when incomplete tick killing occurs sequentially across the active tick season.

Finally, bifenthrin, often currently considered the industry standard in broadcast tick control treatments, was highly effective as both a knockdown and residual treatment in all $4 \mathrm{yr}$, including as a residual 4 wk post-application, similar to other studies (Schulze and Jordan 2019). In the final year of testing, we decreased the bifenthrin concentration by a third of its labeled rate and still had $<2 \%$ recovery of ticks from both the knockdown and residual plots. Despite somewhat lower observed effectiveness in a recent large residential trial (Hinckley et al. 2016), it would seem difficult at this time to dismiss the use of bifenthrin as an effective tool in tick control and tick-borne disease prevention.

\section{Acknowledgments}

The authors thank Patrick McNiece, Jason LaPorte, Shane McLoughlin, Andrew Barao, Adam Peplar, and Chris Schuttert for help in setting up our experimental plots, and Dr. Howard S. Ginsberg and Dr. Steven R. Alm for helping design our study and editing our manuscript. We also would like to thank the following people for donating products for our trials: Patrick Ryan (Envincio) for the EcoPCO EC-X and Essentria IC ${ }^{3}$ in 2012; Chris Fletcher (Bartlett Tree Experts) for the Talstar Professional (2012, 2013, 2015) and UP-Star Gold (2014); Jerrod Leland (Novozyme) for the Met52 EC (2012, 2013); Trevor Nelson for the EcoEXEMPT IC ${ }^{2}$ and EcoADJUVANT (2013), Essentria IC $^{3}$ (2013, 2014), and Private label 1 (2015); Marc Dolan (Centers for Disease Control and Prevention [CDC]) for the nootkatone (2014); Wildflower Farms for the Tick Stop (2014); and Brian Kelly for Private label 2 (2015). Any use of trade, firm, or product names is for descriptive purposes only and does not imply endorsement by the U.S. government. This research was supported by the Centers for Disease Control and Prevention Award 1U01CK000186. 


\section{References Cited}

Abbott, W. S. 1925. A method of computing the effectiveness of an insecticide. J. Econ. Entomol. 18: 265-267.

Benjamin, M. A., E. Zhioua, and R. S. Ostfeld. 2002. Laboratory and field evaluation of the entomopathogenic fungus Metarbizium anisopliae (Deuteromycetes) for controlling questing adult Ixodes scapularis (Acari: Ixodidae). J. Med. Entomol. 39: 723-728.

Berger, K. A., H. S. Ginsberg, K. D. Dugas, L. H. Hamel, and T. N. Mather. 2014. Adverse moisture events predict seasonal abundance of Lyme disease vector ticks (Ixodes scapularis). Parasit. Vectors 7: 181.

Bharadwaj, A., and K. C. Stafford, $3^{\text {rd }}$. 2010. Evaluation of Metarhizium anisopliae strain F52 (Hypocreales: Clavicipitaceae) for control of Ixodes scapularis (Acari: Ixodidae). J. Med. Entomol. 47: 862-867.

Bharadwaj, A., K. C. Stafford, $3^{\text {rd }}$, and R. W. Behle. 2012. Efficacy and environmental persistence of nootkatone for the control of the blacklegged tick (Acari: Ixodidae) in residential landscapes. J. Med. Entomol. 49: 1035-1044.

Butler, A. D., T. Sedghi, J. R. Petrini, and R. Ahmadi. 2016. Tick-borne disease preventive practices and perceptions in an endemic area. Ticks Tick. Borne. Dis. 7: 331-337.

Centers for Disease Control and Prevention (CDC). 2019a. Lyme disease charts and figures: historical data (Lyme disease—reported cases" by year, United States, 1996-2018). (https://www.cdc.gov/lyme/stats/graphs.html). Accessed 22 November 2020.

Centers for Disease Control and Prevention (CDC). 2019b. Reported cases of Lyme disease by state or locality, 2009-2018. (https://www.cdc.gov/lyme/ stats/tables.html). Accessed 22 November 2020.

Childs, J., R. E. Shope, D. Fish, F. X. Meslin, C. J. Peters, K. Johnson, E. Debess, D. Dennis, and S. Jenkins. 1998. Emerging zoonoses. Emerg. Infect. Dis. 4: 453-454.

Connally, N. P., A. J. Durante, K. M. Yousey-Hindes, J. I. Meek, R. S. Nelson, and R. Heimer. 2009. Peridomestic Lyme disease prevention: results of a population-based case-control study. Am. J. Prev. Med. 37: 201-206.

Dolan, M. C., R. A. Jordan, T. L. Schulze, C. J. Schulze, M. C. Manning, D. Ruffolo, J. P. Schmidt, J. Piesman, and J. J. Karchesy. 2009. Ability of two natural products, nootkatone and carvacrol, to suppress Ixodes scapularis and Amblyomma americanum (Acari: Ixodidae) in a Lyme disease endemic area of New Jersey. J. Econ. Entomol. 102: 2316-2324.

Eisen, L., and M. C. Dolan. 2016. Evidence for personal protective measures to reduce human contact with blacklegged ticks and for environmentally based control methods to suppress host-seeking blacklegged ticks and reduce infection with Lyme disease spirochetes in tick vectors and rodent reservoirs. J. Med. Entomol. 53: 1063-1092.

Elias, S. P., C. B. Lubelczyk, P. W. Rand, J. K. Staples, T. W. St Amand, C. S. Stubbs, E. H. Lacombe, L. B. Smith, and R. P. Smith, Jr. 2013. Effect of a botanical acaricide on Ixodes scapularis (Acari: Ixodidae) and nontarget arthropods. J. Med. Entomol. 50: 126-136.

Garza-Hernández, J. A., F. Reyes-Villanueva, T. L. Russell, M. A. Braks, A. M. Garcia-Munguia, and M. A. Rodríguez-Pérez. 2015. Copulation activity, sperm production and conidia transfer in Aedes aegypti males contaminated by Metarhizium anisopliae: a biological control prospect. PLoS Negl. Trop. Dis. 9: e0004144.

Ginsberg, H. S., T. A. Bargar, M. L. Hladik, and C. Lubelczyk. 2017. Management of arthropod pathogen vectors in North America: minimizing adverse effects on pollinators. J. Med. Entomol. 54: 1463-1475.

Gould, L. H., R. S. Nelson, K. S. Griffith, E. B. Hayes, J. Piesman, P. S. Mead, and M. L. Cartter. 2008. Knowledge, attitudes, and behaviors regarding Lyme disease prevention among Connecticut residents, 1999-2004. Vector Borne Zoonotic Dis. 8: 769-776.

Herrington, J. E. 2004. Risk perceptions regarding ticks and Lyme disease: a national survey. Am. J. Prev. Med. 26: 135-140.

Hinckley, A. F., J. I. Meek, J. A. E. Ray, S. A. Niesobecki, N. P. Connally, K. A. Feldman, E. H. Jones, P. B. Backenson, J. L. White, G. Lukacik, et al. 2016. Effectiveness of residential acaricides to prevent lyme and other tick-borne diseases in humans. J. Infect. Dis. 214: 182-188.

Hook, S. A., C. A. Nelson, and P. S. Mead. 2015. U.S. public's experience with ticks and tick-borne diseases: results from national HealthStyles surveys. Ticks Tick. Borne. Dis. 6: 483-488.
Hunter, D. M. 2005. Mycopesticides as part of integrated pest management of locusts and grasshoppers. J. Orthoptera Res. 14: 197-201.

Jordan, R. A., and T. L. Schulze. 2019. Availability and nature of commercial tick control services in three Lyme disease endemic states. J. Med. Entomol. 57: 807-814.

Jordan, R. A., M. C. Dolan, J. Piesman, and T. L. Schulze. 2011. Suppression of host-seeking Ixodes scapularis and Amblyomma americanum (Acari: Ixodidae) nymphs after dual applications of plant-derived acaricides in New Jersey. J. Econ. Entomol. 104: 659-664.

Kirkland, B. H., G. S. Westwood, and N. O. Keyhani. 2004. Pathogenicity of entomopathogenic fungi Beauveria bassiana and Metarhizium anisopliae to Ixodidae tick species Dermacentor variabilis, Rhipicephalus sanguineus, and Ixodes scapularis. J. Med. Entomol. 41: 705-711.

Lee, S. J., S. Kim, J. S. Yu, J. C. Kim, Y.-S. Nai, and J. S. Kim. 2015. Biological control of Asian tiger mosquito, Aedes albopictus (Diptera: Culicidae) using Metarhizium anisopliae JEF-003 millet grain. J. Asia Pac. Entomol. 18: 217-221.

Leemon, D. M., L. B. Turner, and N. N. Jonsson. 2008. Pen studies on the control of cattle tick (Rhipicephalus (Boophilus) microplus) with Metarhizium anisopliae (Sorokin). Vet. Parasitol. 156: 248-260.

Mather, T. N., and M. E. Mather. 1990. Intrinsic competence of three ixodid ticks (Acari) as vectors of the Lyme disease spirochete. J. Med. Entomol. 27: 646-650.

Mullin, C. A., J. Chen, J. D. Fine, M. T. Frazier, and J. L. Frazier. 2015. The formulation makes the honey bee poison. Pestic. Biochem. Physiol. 120: $27-35$.

Niesobecki, S., A. Hansen, H. Rutz, S. Mehta, K. Feldman, J. Meek, L. Niccolai, S. Hook, and A. Hinckley. 2019. Knowledge, attitudes, and behaviors regarding tick-borne disease prevention in endemic areas. Ticks Tick. Borne. Dis. 10: 101264.

Piesman, J. 2006. Strategies for reducing the risk of Lyme borreliosis in North America. Int. J. Med. Microbiol. 296(Suppl. 40): 17-22.

Rand, P. W., E. H. Lacombe, S. P. Elias, C. B. Lubelczyk, T. St Amand, and R. P. Smith, Jr. 2010. Trial of a minimal-risk botanical compound to control the vector tick of Lyme disease. J. Med. Entomol. 47: 695-698.

Rosenberg, R., N. P. Lindsey, M. Fischer, C. J. Gregory, A. F. Hinckley, P. S. Mead, G. Paz-Bailey, S. H. Waterman, N. A. Drexler, G. J. Kersh, et al. 2018. Vital signs: trends in reported Vectorborne Disease Cases United States and Territories, 2004-2016. Morb. Mortal. Wkly Rep. 67: 496-501.

Schroer, S., H. Sermann, C. Reichmuth, and C. Büttner. 2001. Effectiveness of different emulsifiers for neem oil against the western flower thrips (Thysanoptera, Thripidae) and the warehouse moth (Lepidoptera, Pyralidae). Meded. Rijksuniv. Gent. Fak. Landbouwkd. Toegep. Biol. Wet. 66: 463-471.

Schulze, T. L., and R. A. Jordan. 2019. Early season applications of bifenthrin suppress host-seeking Ixodes scapularis and Amblyomma americanum (Acari: Ixodidae) nymphs. J. Med. Entomol. 57: 797-800.

Stafford, K. C. 2007. Tick management handbook: an integrated guide for homeowners, pest control operators, and public health officials for the prevention of tick-associated disease. Connecticut Agricultural Experiment Station, New Haven, CT.

Stafford, K. C., $3^{\text {rd }}$, and S. A. Allan. 2010. Field applications of entomopathogenic fungi Beauveria bassiana and Metarhizium anisopliae F52 (Hypocreales: Clavicipitaceae) for the control of Ixodes scapularis (Acari: Ixodidae). J. Med. Entomol. 47: 1107-1115.

U.S. Environmental Protection Agency (EPA). 2020. Minimum risk pesticide: definition and product confirmation. (https://www.epa.gov/minimum-risk-pesticides/ minimum-risk-pesticide-definition-and-product-confirmation). Accessed 11 June 2020.

Wassermann, M., P. Selzer, J. L. M. Steidle, and U. Mackenstedt. 2016. Biological control of Ixodes ricinus larvae and nymphs with Metarbizium anisopliae blastospores. Ticks Tick. Borne. Dis. 7: 768-771.

Wright, C., A. Brooks, and R. Wall. 2004. Toxicity of the entomopathogenic fungus, Metarhizium anisopliae (Deuteromycotina: Hyphomycetes) to adult females of the blowfly Lucilia sericata (Diptera: Calliphoridae). Pest Manag. Sci. 60: 639-644. 